\title{
Türkiye'de Faaliyet Gösteren Bireysel Emeklilik Şirketlerinin Performansının Entropi ve COPRAS Yöntemi ile Değerlendirilmesi*
}

\author{
Aynur ACER ${ }^{* *}$, Tolga GENÇ ${ }^{* * *}$, Sait Erdal DINÇER ${ }^{* * * *}$
}

\begin{abstract}
Öz
Bireysel emeklilik sistemi Türkiye'de gönüllülük esasına dayanan, katılımcıları uzun vadeli araçlara yönlendirerek yaşlılıktaki gelirlerini garanti altına almayı amaçlayan ve sosyal güvenlik sisteminin finansal yükünü azaltarak sosyal katılımcıların yaşam kalitesinin artmasını hedefleyen bir sistemdir. Bu çalışmada 2018 yılı verileri kullanılarak Türkiye'de faaliyet gösteren 17 bireysel emeklilik şirketinin performansı katılımcı sayısı, katılımcı fon tutarı, katkı payı tutarı, devlet katkısı fon tutarı ve emeklilik teknik gider kriterleri ele alınarak Entropi ve COPRAS yöntemiyle analiz edilmiștir. Analiz sonucunda katılımcı fon tutarı kriteri en yüksek önem derecesine sahip kriter olarak belirlenmiștir.

Anahtar Kelimeler: Bireysel Emeklilik Sistemi, COPRAS Yöntemi, Entropi Yöntemi, Çok Kriterli Karar Verme, Performans Değerlendirme.

\section{Performance Evaluation of Private Pension Companies Operating in Turkey by Entropy and COPRAS Method}

\begin{abstract}
In Turkey private pension system is a system based on the principle of volunteering, aims to guarantee the income of the old age by directing the participants to long-term vehicles and aims to increase the quality of life of social participants by reducing the financial burden of the social security system. In this study using 2018 data, the performance of the 17 private pension companies operating in Turkey were analyzed considering the criteria that the number of participants, participant fund amount, contribution amaunt, the state contribution amaunt and superannuation technical expence by methods of Entropy and COPRAS. As a result of the analysis, the participant fund amount criterion has been identified with the highest weight.

Keywords: Private Pension System, COPRAS Method, Entropi, Multi Criteria Decision Making, Performance Evaluation.
\end{abstract}

\section{Özgün Araştırma Makalesi (Original Research Article) \\ Geliş/Received: 27.05 .2019}

Kabul/Accepted: 27.02 .2020

DOI: https://dx.doi.org/10.17336/igusbd.560975

*Bu çalışma, 17-20 Ekim 2018 tarihinde Antalya'da düzenlenen “19. Uluslararası Ekonometri, Yöneylem Araștırması ve İstatistik Sempozyumu 2018”de sunulan bildirinin genișletilmiș halidir.

${ }^{* *}$ Dr. Öğr. Üyesi, İstanbul Arel Üniversitesi, U.B.Y.O., Uluslararası Loj. ve Taş. Bölümü, İstanbul,

Türkiye, E-Posta: aynuracer@arel.edu.tr, ORCID ID https://orcid.org/0000-0002-7315-7020

*** Doç. Dr., Marmara Üniversitesi, İktisat Fakültesi, Ekonometri Bölümü, İstanbul, Türkiye,

E-Posta: tolga95@yahoo.com, ORCID ID https://orcid.org/0000-0002-6134-5964

**** Doç. Dr., Marmara Üniversitesi, İktisat Fakültesi, Ekonometri Bölümü, İstanbul, Türkiye,

E-Posta: edincer@marmara.edu.tr, ORCID ID https://orcid.org/0000-0002-8310-1418 


\section{Giriş}

Günümüzde nüfusun yaşlanmasıyla birlikte bireyler emeklilikteki gelirlerini garanti altına almak istemekte ve ek bir gelir elde edebilmek için sosyal güvenlik sistemi haricinde farklı bir emeklilik sisteminin desteğine ihtiyaç duymaktadır. Bu ihtiyaç sonucu ortaya çıkan bireysel Emeklilik sistemi (BES) içinde özel emeklilik fonları oluşturulmuş ve bireyler BES şirketleri tarafından ekonomiye ciddi kaynak sağlayan yatırım araçlarına yönlendirilmiștir. Șen ve Memiș (2000, s. 29) tarafindan "yükümlülükleri önceden belirlenen bir sözleşme çerçevesinde, çalıșanların bireysel hesaplarına düzenli olarak yatırılan katkı paylarının emeklilik dönemi başlangıcına kadar etkin bir fon yönetimiyle değerlendirilmesi esasına dayalı organize bir emeklilik sigorta çeşidi” olarak tanımlanan özel emeklilik fonları, özellikle gelir düzeyi düșük olan bireylerin çalıșma süresi boyunca tasarruf ederek emeklilik döneminde yaşam kalıtesini arttırmayı amaçlayan bir yatırım aracıdır. Temeli gönüllülük esasına dayalı olan bu uygulama sayesinde șirketler tarafından BES'e dahil edilerek verimli yatırım araçlarına yönlendirilen katılımcılar, hem ek gelir elde ederek yaşam kalitesini arttırmayı hedeflemekte hem de uzun vadede tasarruf sağlanmaktadır.

Dünya genelinde yaşlı nüfus için uygulanan sosyal politikalardaki yetersizlik emeklilik sisteminin yenilenmesini zorunlu kılmış ve her ülke kendi nüfusu için alternatif sistemler ve fonlar geliştirmeye çalışmıștır. Gelişmiş ülkelerde çalışanların kendi çabaları sonucu uygulanan özel emeklilik fonları, gelişmekte olan ülkelerde devlet teșviki ve zorunlu uygulamalar șeklinde ortaya çlkmıștır. 1862'de Avustralya'da New South Wales Bank'ın uyguladığı özel emeklilik fonu bilinen ilk uygulamadır (Dalğar, 2007, s. 107). 1875 yılında ABD'de Amerikan Demiryolu Şirketi (The American Express Company) aracılığıyla uygulamaya konulan ilk özel emeklilik sistemi (Özer ve Gürel, 2014, s. 160), Avrupa'da 1940’lı yıllarda yayılmaya başlamıştır. Bu sıralamayı sırasıyla 1980 yılında Şili'de ortaya çıkan ilk emeklilik reform sonucu uygulanan özel emeklilik sistemi, 1994 yll Arjantin ve 1997 yılı Meksika'da yapılan özel emeklilik reformları takip etmiștir (Şener ve Akın, 2010, s. 292).

Türkiye'de BES'in tarihsel gelișimi incelendiğinde; Bireysel Emeklilik Komisyonu tarafından hazırlanan ve Bakanlar Kurulu tarafından incelenen "Bireysel Emeklilik Tasarruf ve Yatırım Sistemi Kanunu Tasarısı" Türkiye Büyük Millet Meclisi Başkanlığı'na 16 Mayıs 2000 tarihinde sunulmuştur. Kanun, 7 Nisan 2001 tarihinde 24366 sayılı Resmi Gazete'de yayınlanarak 7 Ekim 2001 tarihinde yürürlüğe girmiştir. 10 Temmuz 2003 senesinde ilgili mevzuat uyarınca Hazine Müsteşarlığı görev ve yetkilendirmesi çerçevesinde "Emeklilik Gözetim Merkezi" kurulmuştur. 10 Ağustos 2016 tarihinde 6740 sayılı Resmi Gazete'de yayımlanan Bireysel Emeklilik Tasarruf ve Yatırım Sistemi Kanunu'nda Değişiklik Yapılmasına Dair Kanun ile çalışanların otomatik olarak bir emeklilik planına dahil etmesine ilişkin esaslar düzenlenmiş ve 1 Ocak 2017 tarihi itibariyle yürürlüğe girmiștir. Son olarak 2 Ocak 2017 tarihinde "Çalışanların İşverenleri Aracılığıla Otomatik Olarak Emeklilik Planına Dahil Edilmesine İlişkin Usul ve Esaslar Hakkında Yönetmelik" 29936 sayılı Resmi Gazete'de yayınlanmıștır (Bu bilgiler https://www.egm.org.tr/otomatik-katilim/tarihce/'den derlenerek oluşturulmuştur). EGM Bireysel Emeklilik Sistemi Gelişim Raporu'na göre 31.12.2017 tarihi itibariyle sisteme kayıtlı çalışan sayısı bir önceki yıla oranla \%4 artarak 6.924.945'e ulașmıștır. Emeklilik yatırım fonları toplam büyüklüğü 67.677.308.661 TL, toplam devlet katkısı fonları büyüklüğü 10.141.315.793 TL ve faaliyet gösteren emeklilik şirketi sayısı 18'dir.

Bireysel Emeklilik sisteminin ulusal tasarruf oranlarının artmasıyla birlikte ülke ekonomisine büyük katkısı olmakta ve finansal piyasaları destekleyici bir rol oynamaktadır. Türkiye'de ilk olarak 27 Ekim 2003 tarihinde fiili olarak hayata geçirilen Bireysel Emeklilik Sistemi (BES)'nin uygulamaları ülkeden ülkeye farklılık göstermekte, 
gelişmiş ülkelerde sosyal güvenlik sisteminin tamamlayıcısı olarak hizmet vermektedir. Ülkemizde Hazine Müsteşarlığı koordinasyonluğunda bir sosyal güvenlik reformu olarak yeni ve hızla gelișen bir alan olan ve hayat sigortası şirketlerinin önemli bir bölümünün emeklilik şirketlerine dönüşmesiyle ortayan çıkan BES uygulamalarının temel amacı; özel emeklilik fonlarıyla bireylerin uzun vadeli birikimlerinin sermaye piyasalarına aktarılarak verimli bir şekilde değerlendirilmesi ve sosyal güvenlik sisteminin finansal yükünün hafifletilerek makro düzeyde sosyal refahın sağlanmasıdır. Bir BES şirketiyle sözleșme imzalayarak sisteme dahil edilen çalışanların bu sistemden emekli olabilmesi için sisteme ilk giriş yaptığı tarihten itibaren 10 yıl süreyle katkı payını ödeyerek sistemde kalması ve 56 yaşını doldurmuş olması gerekmektedir.

\section{BES Şirketlerinin Performans Değerlendirmesi ile İlgili Literatür Taraması}

Ulusal tasarruf fonlarının arttırılması, ekonomi ve sermaye piyasasına uzun vadeli fonların kazandırılması ve dış finansmana duyulan ihtiyacın azaltılması (EGM Raporu, 2017, Erişim Tarihi: 10.02.2019) amaciyla düzenlenen bir uygulama olan bireysel emeklilik sistemi ile ilgili literatürde çok kriterli karar verme yüntemleri kullanılarak yapılan çalışmalar aşağıda yer almaktadır:

Amerikan sigorta şirketlerinin etkinliklerini gelir ve maliyet açısından değerlendiren Cummins vd. (1998) çalışmalarında yöntem olarak Malmquist-Toplam Faktör Verimliliği Endeksi'ni kullanmış ve yüksek gelire sahip olan şirketlerin düşük gelire sahip olan şirketlere göre daha etkin olduğu sonucuna ulaşmıştır.

Çiftçi (2004), 1998-2002 yllları arasında Türkiye'de faaliyet gösteren sigorta şirketlerini hayat ve hayat dışı faaliyetlerine göre iki grupta değerlendirmiş ve etkinlik düzeylerini Veri Zarflama Analizi (VZA) ile incelemiştir.

Tayvan'da sigorta şirketlerinin etkinliklerini 1997-1999 yıllarına göre inceleyen Hao ve Chou (2005), Stokastik Sınır Analizi (SSA) yöntemini kullanarak firmaların performansının piyasa payı, ürün farklılaștırması ve ölçek etkinliği ile doğru orantılı olarak değiștiği sonucunu elde etmiştir. Tayvan'daki sigorta şirketlerinin performanslarının değerlendirilmesi amacıyla Fan ve Cheng (2009) tarafından yapılan başka bir çalışmada ise Analitik Hiyerarşi Prosesi (AHP) ve TOPSIS yöntemleri kullanılmıștır.

Köse (2010) girdi değişkenleri olarak personel sayısı, toplam maliyet ve toplam özkaynak; çıtı değişkenleri olarak ise toplam prim ve toplam gelirleri kullandığı çalışmasında yöntem olarak Veri Zarflama Analizini (VZA) kullanmıştır. 2004-2008 yılı hayat ve emeklilik sigortası şirketlerinin etkinliğinin araştırıldığı çalışmada, alternatif olarak değerlendirilen şirketlerden üç tanesi belirtilen tarihler için verimli ve istikrarlı bulunmuştur.

Ege ve Coşkun (2011) Türkiye'de faaliyet gösteren on bireysel emeklilik şirketinin 80 yatırım fonunun, 2008-2010 ylları arasındaki performansını Sharpe ve Modigliani yöntemleri ile analiz etmiştir. En yüksek ve en düşük yatırım fonlarının belirlenmek istendiği çalışmada, özel emeklilik fonlarının etkin bir şekilde yönetilemediği sonucuna ulaşılmıştır.

Gri ilişkisel analiz yöntemi ile türk sigortacılık sektöründe faaliyet gösteren üç sigorta şirketinin finansal performansını değerlendiren Peker ve Baki (2011), kriter olarak likidite, kaldıraç ve karlılık oranlarını kullanmıştır ve likidete oranı yüksek olan şirketin finansal performansının da yüksek olduğu sonucunu elde etmiştir.

Dalkılıç (2012), 2008-2010 dönemi Türkiye'de hayatdışı branşında faaliyet gösteren 27 sigorta şirketlerinin etkinliklerini VZA-BCC ve Malmquist toplam faktör verimlilik endeksi kullanarak değerlendirmiștir. Girdi olarak öz kaynaklar, çalışan sayısı, acente sayısı, sabit varlıklar değişkenlerinin; çıktı olarak ise toplam sigortacılık teknik 
karşılıkları, toplam prim üretimi ve ödenen tazminatlar değişkenlerinin kullanıldığı bu çalışmada 2008 yılına göre sigorta şirketlerinin etkinliğinin 2009 yılında arttığı ve 2010 yılında ise düşüş gösterdiği sonucu elde edilmiștir.

Türkiye'de hayatdışı ve hayat/emeklilik sigorta şirketlerinin 2007-2011 yılları arasındaki performansını TOPSİS yöntemi ile değerlendiren Akyüz ve Kaya (2013), hayatdışı sigorta şirketlerinin 2007 yılında en yüksek ve 2008 yılında en düşük dönemini yaşadığı sonucuna ulaşmıştır. Diğer taraftan hayat/emeklilik şirketlerinin ise 2009 yılında başarısız iken 2007 yılında ise başarılı bir dönemi geçirdiği sonucu elde edilmiştir.

Genç vd. (2015) bireysel emeklilik şirketlerini fon getiri oranı, şirketlerin bilgileri, sistemden çıkış kolaylığı, erişim olanakları ve elemanların nitelikleri kriterlerine göre çok kriterli karar verme yöntemlerinden MACBETH yaklaşımı ile değerlendirmiş̦tir.

Kula vd. (2016) çalıșmasında BİST bünyesinde işlem gören yedi sigorta şirketi ve bir bireysel emeklilik şirketinin finansal performansını 2013 yılı verileri için Gri İlişkisel Analiz yöntemi ile incelemiştir. Şirketlerin yarısının sermaye yapılarının etkin olduğu, cari oran ve karlılık oranları düşük olan şirketlerin etkinlik seviyesinin de düşük olduğu sonucu elde edilmiștir.

2010-2013 yıllarına ait bilanço verilerinden yararlanarak Türk sigortacılık sektöründe hayatdışı branşlarda faaliyet gösteren sigorta şirketlerinin performanslarını sekiz finansal oranı kriter alarak inceleyen Bülbül ve Köse (2016) çalışmasında yöntem olarak Promethee I ve Promethee II yöntemlerini kullanmıştır. Hayatdışı sigorta şirketleri performanslarına göre sıralanarak istikrarsız şirketler belirlenmiş ve şirketlerin performanslarının değișiminde rol oynayan değişkenlere bağlı olarak bu istikrarsızlığın olası nedenleri tespit edilmiștir.

Özcan ve Ömürbek (2016) çalışmasında BIST'te faaliyet gösteren sigorta şirketlerinin performanslarını 10 finansal orana (Cari Oran, Nakit Oranı, Varlık Devir Hızı, Borç Oranı, Brüt Kar Marjı, Net Kar Marjı, Öz Sermaye Karlılığı, Yatırım Karlılığı, Fiyat/Kazanç Oranı ve Piyasa Değeri-Defter Değeri Oranı) göre MOORA Oran Metodu, Referans Noktası Yaklaşımı ve Tam Çarpım Formu Yöntemi kullanarak Multi-MOORA yöntemi ile analiz etmiștir.

Personel giderleri, yazllan primler, toplam aktifler, öz sermaye ile ödenen tazminatlar ve teknik karşılıklar toplamı olmak üzere 5 adet kriterin ağırlıklarını belirlemede AHP'yi kullanan Çakır (2016), 2014 yılı için BIST'e faaliyet gösteren beş sigorta şirketlerini değerlendirmiştir. Alternatiflerin Bulanık VİKOR yöntemi ile değerlendirildiği ve sıralandığı çalışmada F şirketi en iyi şirket seçilmiştir.

BİST'te faaliyet gösteren altı sigorta şirketinin 2011-2015 yılları arasındaki finansal performanslarını Bulanık Shannon Entropi Tabanlı Bulanık TOPSíS yöntemiyle inceleyen Aytekin ve Karamaşa (2017); nakit, borç, net kar marjı, öz sermaye karlılığı ve yatırım karlılığı finansal oranlarını değişken olarak çalışmasında kullanmıștır.

Sırbistan'da 2007-2014 yılları arasındaki verilere göre tüm sigorta şirketlerinin performansını değerlendiren Ksenija vd. (2017) çalışmasında özkaynaklar, iş aktifleri, diğer borç ve yükümlülükler, finansal gelirler ve sigorta maliyeti olmak üzere beş finalsal kriteri kullanmıştır. Bulanık Analitik Hiyerarşi Prosesi (BAHP) ile kriter ağırlıkları belirlenmiş ve TOPSİS yöntemiyle performansları sıralanmıștır.

Göktolga ve Karakış (2018) bireysel emeklilik şirketlerinin finansal performanslarını değerlendirdiği; özkaynak karlılık, toplam aktif karlılık, kaldıraç oranı, teknik kar oranı, net kar prim oranı, hasar prim oranı ve yatırım gelirleri oranını kriter olarak kullandığı çalışmasında finansal oranların ağırlıklarının belirlenmesinde Bulanık AHP'yi kullanmıștır. Uygulamada 2014-2016 yılları arasındaki finansal tablolardan yararlanılarak elde edilen veriler Vise Kriterijumska Optimizacija I Kompromisno Resenje (VIKOR) yöntemleri ile analiz edilmiş ve BES şirketlerinin performansları sıralanmıştır. 
Perçin ve Sönmez (2018) Bütünleşik Entropi ve TOPSíS yöntemini kullanarak Borsa İstanbul'da işlem gören Ak Sigorta, Anadolu Anonim Türk Sigorta Şirketi, Anadolu Hayat Emeklilik, Avivasa Emeklilik/Hayat Anonim Şirketi ve Güneş Sigorta şirketlerinin finansal performansını analiz etmiştir. Beş şirketin performanslarının değerlendirilmesinde karlılık, faaliyet, kaldıraç ve likidite oranları kullanılmış ve Ak sigorta şirketi BIST'te işlem gören en yüksek performansa sahip sigorta şirketi seçilmiştir.

Sigortacılık sektörüyle ilgili çok kriterli karar verme yöntemlerinin kullanıldığı literatür incelendiğinde en bașta VZA, Malmquist-Toplam Faktör Verimliliği Endeksi, Stokastik Sınır Analizi, AHP, TOPSIS, Gri İlişkisel Analiz gibi yöntemlerin sıklıkla tercih edildiği görülmektedir. Bu açıdan bakıldığında Karmaşık Nisbi Değerlendirme Yöntemi olarak bilinen COPRAS yöntemi, BES șirketlerinin performansının değerlendirilmesinde daha önceki hiç bir çalışmada kullanılmamıștır.

Türkiye'de bireysel emeklilik hizmeti veren sigorta şirketlerinin faaliyetlerinin COPRAS yöntemi ile değerlendirildiği bu çalışmada 2018 yılı verilerinden yararlanılmıştır. Alternatif olarak yer alan BES şirketleri katılımcı sayısı, katılımcı fon tutarı, katkı payı tutarı, devlet katkısı fon tutarı ve teknik giderler kriterlerine göre değerlendirilmiş ve şirketlerin performanslarına göre sıralaması yapılmıștır.

\section{Kullanılan Yöntemin Tanımlanması}

İnsan hayatının hemen hemen her safhasında düşünsel bir süreç olarak karşımıza çıkan karar verme, alternatif olarak bilinen birden fazla seçenek arasından en az bir amaç ve ölçüte göre en uygun alternatifin seçilmesi sürecidir (Dağdeviren ve Eren, 2001). Günlük sorunların hızla değiştiği ve yeni problemlerin ortaya çıtığı bilgi çağında karar vericiler en iyi seçeneği bulmakta zorlanmaktadır. Alternatifler arasından seçim yaparken birden fazla kriteri dikkate alarak birden fazla amaca etkin bir şekilde karşılık gelen en uygun seçeneği tercih etmek zorundadır (Acer ve Dinçer, 2018). Sonuçların önceden tahmin edilememesi, verilerin yetersiz olması, kesin olmaması veya dışsal faktörlerin etkisiyle ihtimal dahilinde olması gibi nedenler karar vermede belirsizlik durumlarını ortaya çıkarmaktadır. Bu belirsizlik durumunu azaltmak amacıyla karar verici veya yönetici bir karar alma sürecinde doğru ve güvenilir tahminlerde bulunabilmek amaciyla bilimsel yaklaşımları kullanabilmekte ve en iyi alternatifi bu yöntemler sayesinde tercih edebilmektedir. Birden fazla kriteri ele alarak performans ve etkinliğin değerlendirilmesinde kullanılan yöntemler üç başlık atında toplanabilmektedir:

Birden fazla girdi ve çıtının birbirine oranlanmasıyla elde edilen ve çok boyutlu bir analiz olan Matematiksel Programlama Yöntemleri parametrik (stokastik üretim sınırı yaklaşımı, serbest dağılım yaklaşımı ve kalın sınır yaklaşımı) ve parametrik olmayan teknikler (VZA, Malmquist toplam faktör verimliliği endeksi yöntemi, serbest atılabilir zarf yaklaşımı) şeklinde ikiye ayrılmaktadır.

Konjoint analizi ve regresyon analizi çok değişkenli verilerin analizinde sıklıkla kullanılan istatistiksel yöntemlerdir.

Çok Kriterli Karar Verme (ÇKKV) yöntemleri hem kalitatif hem de kantitatif verilerin değerlendirilmesinde kullanılan bir matamatiksel modelleme türüdür. $\mathrm{Bu}$ yöntemlerden AHP, analitik ağ süreci, TOPSİS, Gri İlişkisel Analiz, VİKOR yöntemleri etkinlik ölçümü ve performans değerlemelerde en fazla kullanılan tekniklerdir.

İşletmelerin ve sektörlerin performanslarının değerlendirilmesinde ve ideal alternatifin belirlenmesinde ÇKKV yöntemleri sıklıkla kullanılmaktadır. Kriter ve alternatif sayısının fazla olmadığı karar verme problemlerinde, karar verici sorun yaşamayabilir. Fakat birçok kriterin ve alternatifin yer aldığı problemlerde karar verirken matematiksel yöntemlere ihtiyaç duyulmaktadır. Bu durumda karar verici problemleri tüm boyutlarıyla inceleyerek en uygun çözüme ulaşmayı hedeflemektedir. En uzlaşıcı 
çözümü elde etmek için elindeki birbiriyle çelișen kriterleri değerlendirip birleștirerek alternatifleri sıralayabilir, gruplandırabilir veya aralarından seçim yapabilir (Genç, 2013, s. 122)

Bir karar probleminin çözümü ve alternatiflerin performansının değerlendirilmesinde çeşitli ÇKKV yöntemlerinden hangi yöntemin seçilmesi gerektiğinin belirlenmesi önemli bir aşamadır. Bir o kadar önemli olan kriter ağırlıklarının hesaplanmasında kullanılan yöntemler, subjektif yaklaşımlar ve çeşitli matematiksel yaklaşımlar olmak üzere iki grupta değerlendirmektedir. Karar verici ağırlıkların belirlenmesinde subjektif yöntemlerden yararlanabileceği gibi AHP, Bulanık AHP, Entropi gibi literatürde sıklıkla kullanılan ÇKKV yöntemlerinden de faydalanabilmektedir. Kriter ağırlıklarının belirlenmesinde Entropi yönteminin tercih edildiği bu çalışmada, Karmaşık Nisbi Değerlendirme yöntemi olan COPRAS yöntemi ile şirketlerin performansları analiz edilmiştir. Her iki yöntem ile ilgili açıklamalar ve matematiksel notasyonları izleyen bölümde ayrıntılı verilmiştir.

\subsection{Entropi Yöntemi}

ÇKKV yöntemleri içinde kriterlerin nesnel ağırlı̆ının hesaplanmasında kullanılan objektif ağırlıklandırma yöntemlerinden birisi de Entropi yöntemidir. İlk olarak Rudolph tarafından 1865' de termodinamik alanında geliştirilmiş olan ve sonra Shannon (1948) 'un belirsizliğin ölçüsü olarak tanımladığı, fizik, matematik ve enformasyon bilimlerinden alınan "Entropi" kavramı üzerine inşa edilen bu yöntem entropi/ayrık (discrete) olasılık dağılımı ile verilen belirsizliğin miktarının bir kriteridir.

Yöntemde karar matrisinin, nitelik önemine dair bilgiyi bünyesinde barındırdığı düşünülmekte ve bu bilginin veri kümeleri arasındaki karşıtlıklardan ileri geldiği öne sürülmektedir. Entropi yönteminde niteliklerin nesnel ağırlıklarıyla alternatiflerin her niteliğe göre çıktılarının ne kadar karlılaşmış olduğu "karşıtlığının yoğunluğu" ile elde edilmektedir. Bu karşıtlık ne kadar artarsa ilgili nitelik tarafından iletilen bilgi de o kadar fazla olur (Çınar, 2004, s. 103).

Entropi yöntemine göre bir karar probleminde hiyerarşik bir yapı oluşturulmadan kriterlerin önem düzeyleri objektif bir şekilde belirlenir ve AHP, Delphi teknikleri gibi karar vericilerin subjektif yargılarına yer verilmeden veriler analiz edilir (Çakır ve Perçin, 2013, s. 79). Belirsizliğin yüksek olduğu durumlarda kullanılan bu yöntem alternatifler için belirli miktarda bilgileri içeren karar matrisine sahip olunduğu taktirde, kriterlerin ağırlık değerlerini belirlemek için kullanılabilecek bir araçtır (Alp vd., 2015: 69). Entropi yönteminin adımları aşağıda yer almaktadır (Shannon, 1948, Tunca ve diğ., 2016):

Adım 1: Çeşitli ölçü birimlerinden oluşan kriterler ve alternatiflerin yer aldığı karar değişkenleri matrisi eşitlik 1 yardımıyla normalize işlemine tabi tutulur.

$$
r_{i j}=\frac{x_{i j}}{\sum_{1}^{j}\left(x_{i j}\right)}
$$

$\boldsymbol{i}$ : alternatif değeri,

$\mathrm{j}$ : kriter değeri,

rij: normalize edilmiş değerleri,

xij: i. alternatif j. kriter için verilen fayda değerleri

Adım 2: e j'nin entropi değeri Eşitlik 2 yardımıyla hesaplanmaktadır (Eşitlik 2'de yer alan k= entropi katsayısını, rij= normalize edilmiş değerleri ve ej= entropi değerini ifade etmektedir).

$$
\mathrm{e}_{\mathrm{j}}=-\mathrm{k} \sum_{\mathrm{j}=1}^{\mathrm{m}} \mathrm{r}_{\mathrm{ij}} \ln \left(\mathrm{r}_{\mathrm{ij}}\right)
$$


Adım 3: $\mathrm{w}_{\mathrm{j}}$ kriterlerin önem derecesini belirten ağırlık değerleri Eşitlik 3 yardımıyla hesaplanmakta ve her kritere bir ağırlık değeri atanmaktadır.

$$
w_{j}=\frac{1-e_{j}}{\sum_{1}^{m} 1-e_{j}}
$$

Hesaplanan kriterlerin ağırlıkları toplamı her zaman bire eșit olacaktır (Eșitlikteki wj: ağırlık değerini, ej ise entropi değerini ifade etmektedir).

$$
\sum_{1}^{m} w_{j}=1
$$

\subsection{COPRAS Yöntemi}

Zavadskas ve Kaklauskas (1996) tarafından “COmplex PRoportional ASsesment Karmașık Oransal Değerlendirme" olarak bilinen COPRAS adlı bir yöntem geliștirilmiştir. Kriterlerin önem ve fayda derecelerine göre alternatiflerin sıralandığı bu yöntem, kriterlerin ölçüt değerlendirmesinde fayda kriterinin üst düzeye çıkartılması ve faydasız kriterlerin en aza indirgenmesi esasına dayanmaktadır (Podvezko, 2011). Değerlendirme sürecinde hem maksimum hem de minimum edilmek istenen kriterleri ayrı ayrı ele alan COPRAS yöntemi alternatiflerin yarar derecelerini gösterdiği için diğer ÇKKV yöntemlerinden farkıdır. Bu yöntem alternatiflerin birbirleriyle karşılaștırılarak diğer alternatiflerden ne kadar iyi ya da ne kadar kötü olduğunu oransal olarak analiz etmektedir (Aksoy vd., 2015, s. 11-12).

ÇKKV ile ilgili diğer yöntemler ve COPRAS yöntemi kıyaslandığında; diğer yöntemlerde karar vericiler için temel amaç alternatifler arasından mümkün olan en iyi seçeneğin tercih edilmesidir. Bu seçimin yapılmasında ikili karşılaştırma matrisleri ve ideal noktaya yakınlık yaklaşımları kullanılmaktadır. Örneğin PROMETEE ve ELECTRE'de ikili karşılaştırmalar sonucunda sıralama yapılmakta ve alternatif sayısının çok olduğu durumlarda hesaplamalar fazla zaman almaktadır. Fakat COPRAS yönteminde ikili karşılaştırmalar yapılmadığı için diğer yöntemlere göre işlemler daha basit kalmaktadır. Bir başka farklılık da değerlendirme ölçütlerinin bazılarının mümkün olduğunca küçük olması ve istenen problemlerde kullanılabilir olmasıdır (Özdağoğlu, 2013, s. 5).

Çok sayıda alternatifin olduğu problemlerde kolayca uygulanan COPRAS yöntemi ile ilgili farklı alanlarda yapılan çalışmalardan bazıları şu şekildedir: Zavadskas vd. (2004) verimli konut yatırım aracı ve kredi değerlendirmesinde konut kredisi erişim modeli geliştirmede, Andruškevicius (2005) ticaret ve eğlence merkezi inşaasında müteahhit seçiminde, Kaklauskas vd. (2007) emlak piyasasının değerlendirilmesinde, Zagorskas vd. (2007) sürdürülebilir şehir yoğunluğu ölçümünde, Zavadskas vd. (2007) yol tasarım alternatiflerinin değerlendirilmesinde ve Chatterjee \& Chakraborty (2014) esnek imalat sistemi seçiminde COPRAS yöntemini kullanmıştır.

COPRAS Yönteminin adımları aşağıda sıralanmaktadır (Zavadskas vd, 2008; Aktaran: Aksoy vd. 2015, s. 12-14);
$\mathrm{Aj}=\mathrm{i}$. Alternatif
$\mathrm{Cj}=\mathrm{j}$. değerlendirme ölçütü
$\mathrm{i}=1,2, \ldots, \mathrm{m}$
$\mathrm{Wj}=\mathrm{j}$. değerlendirme ölçütünün önem düzeyi $\mathrm{j}=1,2, \ldots$
$\mathrm{Xij}=\mathrm{j}$. değerlendirme ölçütü açısından i. alternatifin değeri olarak ifade edilmektedir.

İlk olarak satırlarında üstünlüklerin sıralanmak istenildiği alternatiflerin $\left(S_{1}, S_{2}\right.$, $\left.S_{m}\right)$, sütunlarında ise kullanılacak değerlendirme kriterlerinin $\left(X_{1}, X_{2}, X_{n}\right)$ yer aldığı bir karar matrisi oluşturulmaktadır. Karar matrisi așağıda Tablo 1'de verilmiştir. 


\begin{tabular}{l|lclc}
\hline \multirow{2}{*}{ Seçenekler } & \multicolumn{4}{|l}{ Kriterler } \\
\cline { 2 - 5 } & $X_{1}$ & $X_{2}$ & $\ldots$ & $X_{n}$ \\
\hline$S_{1}$ & $X_{11}$ & $X_{12}$ & $\ldots$ & $X_{1 n}$ \\
$S_{2}$ & $X_{21}$ & $X_{22}$ & $\ldots$ & $X_{2 n}$ \\
. & $\cdot$ &. & & $\cdot$ \\
$\cdot$ & $\cdot$ &. & \\
$S_{m}$ & $X_{m 1}$ & $X_{m 2}$ & $\ldots$ & $X_{m n}$ \\
\hline
\end{tabular}

Tablo 1: Karar Matrisi

Adım 1: Karar matrisinin değerleri Eşitlik 5'de belirtilen formül yardımıyla normalize işlemine tabi tutulara normalize edilmiş karar matrisi oluşturulur.

$$
x_{i j}^{*}=\frac{x_{i j}}{\sum_{i=1}^{m}\left(x_{i j}\right)} \forall j=1,2, \ldots, n
$$

Adım 2: Normalize edilmiș karar matrisinde elde edilen sütunların Entropi yöntemi uygulanarak elde edilen kriterlerin ağırlık değerleri $\left(w_{j}\right)$ ile çarpımı sonucu Eşitlik 6'daki formül yardımı ile ağırlıklandırılmış karar matrisi oluşturulmaktadır.

$$
D^{\prime}=d_{i j}=x_{i j}^{*} \cdot w_{j}
$$

Adım 3: Bu adımda amaca ulaşmada daha yüksek değerlerin daha iyi durumu gösterdiği ölçütleri ifade eden Faydalı ölçütler ile amaca ulaşmada daha düşük değerlerin daha iyi durumu gösterdiği ölçütleri ifade eden faydasız ölçütler hesaplanmaktadır.

Literatürde yapılan çalışmalarda değerin mümkün olduğunca yüksek olmasının tercih edildiği ölçütler faydalı ölçütler olarak gösterilirken, değerin mümkün olduğunca küçük olmasının tercih edildiği ölçütler faydasız ölçütler şeklinde değerlendirilmektedir. Ağırlıklı normalize edilmiş karar matrisindeki değerlerin toplamı alınarak faydalı ölçütler ve faydasız ölçütler hesaplanmaktadır. Faydalı ölçütlerin hesaplanmasında ağırlıklı normalize edilmiş karar matrisindeki değerlerin toplamı $S_{i+}$, faydasız ölçütlerin hesaplanmasında ise ağırlıklı normalize edilmiş karar matrisindeki değerlerin toplamı $S_{i \text { - }}$ șeklinde simgelenmektedir. $S_{i+}$ ve $S_{i-}$ değerinin hesaplanması așağıda eșitliklerde verilmiștir.

$$
\begin{array}{rl}
S_{i+} & =\sum_{j=1}^{k} d_{i j} \\
\left(7_{a}\right) & j=1,2, \ldots, k \text { faydalı ölçütler } \\
S_{i-}=\sum_{j=k+1}^{n} d_{i j} & j=k+1, k+2, \ldots, n \text { faydası ölçütler }\left(7_{b}\right)
\end{array}
$$

Adım 4: Eşitlik 8 yardımıyla $Q_{i}$ olarak ifade edilen her bir alternatif için göreceli önem değerleri hesaplanmaktadır. Hesaplamalar sonucu en iyi alternatif, en yüksek göreceli önem değerine sahip olan alternatif olarak belirlenmektedir.

$$
r_{i j}=S_{i+}+\frac{\sum_{j=1}^{m} S_{i-}}{S_{i-} x \sum_{i=1}^{m} \frac{1}{s_{i-}}}
$$
edilmektedir.

Adım 5: En yüksek göreceli önem değerleri aşağıdaki Eşitlik 9 yardımıyla elde

$$
Q_{\max }=\text { enbüyü } k\left\{Q_{i}\right\} \forall_{i}=1,2, \ldots, m
$$

Adım 6: Her bir alternatif için $P_{i}$ olarak belirtilen Performans indeksi değeri aşağıda belirtilen Eșitlik 10 yardımıyla hesaplanır.

$$
P_{i}=\frac{Q_{i}}{Q_{\max }} \times 100 \%
$$

Bulunan $P_{i}$ performans değer indeksi 100 olan alternatif en iyi alternatif olarak değerlendirilmektedrir. Performans indeksi değerlerinin büyükten küçüğe doğru sıralanmasıyla alternatiflerin performansları kıyaslanabilmektedir. 


\section{Uygulama}

\section{1. Çalışmanin Amacı ve Kapsamı}

$\mathrm{Bu}$ çalışmada Türkiye'de faaliyet gösteren Bireysel Emeklilik Şirketlerinin performansları COPRAS yöntemi ile değerlendirilmiştir. Yapılan literatür taraması ve uzman görüșleri sonucunda firmaların performansının değerlendirilmesinde katılımcı sayısı, katılımcı fon tutarı, katkı payı tutarı, devlet katkısı fon tutarı ve teknik gider kriterleri kullanılmıștır.

Çalışmada kullanılan katılımcı sayısı, katılımcı fon tutarı, katkı payı tutarı, devlet katkısı fon tutarı verileri 2018 yılı için Emeklilik Gözetim Merkezi (https://www.egm.org.tr)'nin bilgi merkezinden elde edilmiș ve ortalama olarak hesaplanmıștır. Teknik gider verisi ise Türkiye Sigorta Reasürans ve Emeklilik Şirketleri Birliği (https://www.tsb.org.tr/)'nin web sitesinde yer alan “Şirket bazında mali ve Teknik tablolar" incelenerek 2018 yılı için verilen dört dönemlik gelir tablosu incelenerek hesaplanmıștır. Tek bir ana kriter olarak ele alınan teknik gider yıllık fon ișletim gideri, faaliyet giderleri, diğer teknik gider ve ceza ödemeleri alt kriterlerinin toplamından oluşmaktadır.

EGM verilerine göre 2018 yılında (05.01.2018-28.12.2018 tarihleri aralığında) aktif olarak faaliyet gösteren 17 sigorta şirketi yer almaktadır. Uygulamada ise bir BES şirketi mart ayından itibaren faaliyet dışı olduğı için analiz dışı bırakılmıştır. Alternafileri oluşturan BES şirketleri A1, A1, ..., A17 şeklinde değerlendirilmiştir. İlk olarak kriterlerin ağırlıkları hesaplanmıș, sonrasında ise COPRAS yöntemi ile performansları değerlendirilmiștir.

\subsection{Enropi Yöntemiyle Ağırlıkların Hesaplanması}

Entropi yöntemi ile ilgili adımlarının yer aldığı Adım 1'de verilen Eşitlik 1 formülü aracılığıyla aşağıda Tablo 2.'de verilen normalize edilmiș karar matrisi elde edilmiştir.

\begin{tabular}{llllll}
\hline Alternatifler & $\begin{array}{l}\text { Katılımcı } \\
\text { Sayısı }\end{array}$ & $\begin{array}{l}\text { Katılımcıların } \\
\text { Fon Tutarı }\end{array}$ & $\begin{array}{l}\text { Devlet } \\
\text { Katkısı } \\
\text { Fon Tutarı }\end{array}$ & $\begin{array}{l}\text { Katkı } \\
\text { Payı } \\
\text { Tutarı }\end{array}$ & $\begin{array}{l}\text { Teknik } \\
\text { Gider }\end{array}$ \\
\hline A1 & 0,1246 & 0,1969 & 0,1817 & 0,1949 & 0,1967 \\
A2 & 0,1639 & 0,1857 & 0,1979 & 0,1850 & 0,1833 \\
A3 & 0,1714 & 0,1481 & 0,1557 & 0,1483 & 0,1195 \\
A4 & 0,1100 & 0,1385 & 0,1050 & 0,1311 & 0,1275 \\
A5 & 0,0740 & 0,0784 & 0,0745 & 0,0771 & 0,0731 \\
A6 & 0,0882 & 0,0453 & 0,0596 & 0,0497 & 0,0394 \\
A7 & 0,0752 & 0,0414 & 0,0524 & 0,0461 & 0,0413 \\
A8 & 0,0379 & 0,0366 & 0,0366 & 0,0361 & 0,0570 \\
A9 & 0,0152 & 0,0329 & 0,0286 & 0,0309 & 0,0293 \\
A10 & 0,0267 & 0,0267 & 0,0262 & 0,0270 & 0,0377 \\
A11 & 0,0121 & 0,0166 & 0,0130 & 0,0165 & 0,0111 \\
A12 & 0,0272 & 0,0190 & 0,0228 & 0,0208 & 0,0202 \\
A13 & 0,0333 & 0,0139 & 0,0198 & 0,0157 & 0,0239 \\
A14 & 0,0143 & 0,0089 & 0,0118 & 0,0096 & 0,0068 \\
A15 & 0,0152 & 0,0047 & 0,0068 & 0,0046 & 0,0120 \\
A16 & 0,0051 & 0,0046 & 0,0062 & 0,0049 & 0,0097 \\
A17 & 0,0058 & 0,0019 & 0,0014 & 0,0018 & 0,0114 \\
\hline
\end{tabular}

Tablo 2: Normalize Edilmiş Karar Matrisi

Eşitlik 2'nin kullanılarak elde edildiği adım 2'de her bir kriter için hesaplanan $e_{j}$ entropi değerleri Tablo 3.'de verilmektedir. 
Aynur Acer, Tolga Genç, Sait Erdal Dinçer, “Türkiye'de Faaliyet Gösteren Bireysel Emeklilik Şirketlerinin Performansının Entropi ve COPRAS Yöntemi ile Değerlendirilmesi”, İstanbul Gelişim Üniversitesi Sosyal Bilimler Dergisi, 7 (1), Nisan 2020, ss. 153-169.

\begin{tabular}{cccccc}
\hline & Katılımcı SayıSı & $\begin{array}{c}\text { Katılımcıların } \\
\text { Fon Tutarı }\end{array}$ & $\begin{array}{c}\text { Devlet Katkısı } \\
\text { Fon Tutarı }\end{array}$ & $\begin{array}{c}\text { Katkı } \\
\text { Payı } \\
\text { Tutarı }\end{array}$ & $\begin{array}{c}\text { Teknik } \\
\text { Gider }\end{array}$ \\
\hline $\begin{array}{c}\text { Entropi } \\
\text { Değeri }\end{array}$ & 0,8585 & 0,8109 & 0,8253 & & \\
\hline
\end{tabular}

Tablo 3: $e_{j}$ Entropi Değerleri Tablosu

Entropi yöntemine göre kriterlerin ağırlıkları Eşitlik 3'deki formülün yer aldığı son adımda hesaplanmış ve değerler Tablo 4'de belirtilmiştir.

\begin{tabular}{cccccc}
\hline & Katılımcı Sayısı & $\begin{array}{c}\text { Katılımcıların } \\
\text { Fon Tutarı }\end{array}$ & $\begin{array}{c}\text { Devlet } \\
\text { Katkısı Fon } \\
\text { Tutarı }\end{array}$ & $\begin{array}{c}\text { Katkı Payı } \\
\text { Tutarı }\end{array}$ & $\begin{array}{c}\text { Teknik } \\
\text { Gider }\end{array}$ \\
\hline $\begin{array}{c}\text { Hesaplanan } \\
\text { Ağırlıklar }\end{array}$ & 0,1673 & 0,2237 & 0,2066 & 0,2169 & 0,1855 \\
\hline
\end{tabular}

Tablo 4: Entropi Yöntemi Kullanılarak Kriter Ağırlıklarının Belirlenmesi

Tablo 4'de hesaplanan tüm ağırlıklar toplamı 1 elde edilmiștir. Entropi yöntemine göre kriterlerin ağırlıkları değerlendirildiğinde katılımcı fon tutarı kriteri 0,2237 ağırlık değeriyle en önemli kriter olarak yer almaktadır. Bu sıralamayı 0,2169 aralığı ile katkı payı tutarı, 0,2066 aralığı ile devlet katkısı fon tutarı, 0,1855 değeri ile teknik gider ve son olarak 0,1673 ile katılımcı sayısı takip etmektedir.

\subsection{COPRAS Yöntemiyle BES Şirketlerinin Performanslarının} Değerlendirilmesi

COPRAS yönteminin anlatıldığı bölümde yer alan adım 1'de verilen Eşitlik 5 yardımıyla değerler normalize edilerek normalize edilmiş karar matrisine dönüștürülmüştür ve matris aşağıda Tablo 5.'de verilmiștir.

\begin{tabular}{llllll}
\hline $\begin{array}{l}\text { Entropi } \\
\text { Ağırlıkları }\end{array}$ & 0,1673 & 0,2237 & 0,2066 & 0,2169 & 0,1855 \\
\hline Alternatifler & $\begin{array}{l}\text { Katılımcı } \\
\text { Sayısı }\end{array}$ & $\begin{array}{l}\text { Katılımcıların } \\
\text { Fon Tutarı }\end{array}$ & $\begin{array}{l}\text { Devlet } \\
\text { Katkısı Fon } \\
\text { Tutarı }\end{array}$ & $\begin{array}{l}\text { Katkı Payı } \\
\text { Tutarı }\end{array}$ & $\begin{array}{l}\text { Teknik } \\
\text { Gider }\end{array}$ \\
\hline A1 & 0,1246 & 0,1969 & 0,1817 & 0,1949 & 0,1967 \\
A2 & 0,1639 & 0,1857 & 0,1979 & 0,1850 & 0,1833 \\
A3 & 0,1714 & 0,1481 & 0,1557 & 0,1483 & 0,1195 \\
A4 & 0,1100 & 0,1385 & 0,1050 & 0,1311 & 0,1275 \\
A5 & 0,0740 & 0,0784 & 0,0745 & 0,0771 & 0,0731 \\
A6 & 0,0882 & 0,0453 & 0,0596 & 0,0497 & 0,0394 \\
A7 & 0,0752 & 0,0414 & 0,0524 & 0,0461 & 0,0413 \\
A8 & 0,0379 & 0,0366 & 0,0366 & 0,0361 & 0,0570 \\
A9 & 0,0152 & 0,0329 & 0,0286 & 0,0309 & 0,0293 \\
A10 & 0,0267 & 0,0267 & 0,0262 & 0,0270 & 0,0377
\end{tabular}


Aynur Acer, Tolga Genç, Sait Erdal Dinçer, “Türkiye'de Faaliyet Gösteren Bireysel Emeklilik Şirketlerinin Performansının Entropi ve COPRAS Yöntemi ile Değerlendirilmesi”, İstanbul Gelişim Üniversitesi Sosyal Bilimler Dergisi, 7 (1), Nisan 2020, ss. 153-169.

\begin{tabular}{llllll} 
A11 & 0,0121 & 0,0166 & 0,0130 & 0,0165 & 0,0111 \\
A12 & 0,0272 & 0,0190 & 0,0228 & 0,0208 & 0,0202 \\
A13 & 0,0333 & 0,0139 & 0,0198 & 0,0157 & 0,0239 \\
A14 & 0,0143 & 0,0089 & 0,0118 & 0,0096 & 0,0068 \\
A15 & 0,0152 & 0,0047 & 0,0068 & 0,0046 & 0,0120 \\
A16 & 0,0051 & 0,0046 & 0,0062 & 0,0049 & 0,0097 \\
A17 & 0,0058 & 0,0019 & 0,0014 & 0,0018 & 0,0114 \\
\hline
\end{tabular}

Tablo 5: Normalize Edilmiș Karar Matrisi

Eșitlik 6 formülü kullanılarak normalize edilmiş karar matrisi değerleri ile entropi yöntemi kullanılarak elde edilen ağırlıkların çarpımı ile ağırlıklı normalize edilmiş karar matrisi elde edilmiş ve Tablo 6.'da verilmiştir.

\begin{tabular}{llllll}
\hline Alternatifler & $\begin{array}{l}\text { Katılımcı } \\
\text { Sayısı }\end{array}$ & $\begin{array}{l}\text { Katılımcların } \\
\text { Fon Tutarı }\end{array}$ & $\begin{array}{l}\text { Devlet } \\
\text { Katkıs Fon } \\
\text { Tutarı }\end{array}$ & $\begin{array}{l}\text { Katkı Payı } \\
\text { Tutarı }\end{array}$ & $\begin{array}{l}\text { Teknik } \\
\text { Gider }\end{array}$ \\
\hline A1 & 0,02085 & 0,04405 & 0,03754 & 0,04228 & 0,03649 \\
A2 & 0,02743 & 0,04154 & 0,04089 & 0,04012 & 0,03401 \\
A3 & 0,02867 & 0,03313 & 0,03216 & 0,03217 & 0,02218 \\
A4 & 0,01840 & 0,03099 & 0,02170 & 0,02845 & 0,02366 \\
A5 & 0,01238 & 0,01753 & 0,01539 & 0,01672 & 0,01356 \\
A6 & 0,01476 & 0,01013 & 0,01231 & 0,01077 & 0,00730 \\
A7 & 0,01258 & 0,00927 & 0,01082 & 0,01000 & 0,00781 \\
A8 & 0,00635 & 0,00818 & 0,00756 & 0,00783 & 0,01057 \\
A9 & 0,00254 & 0,00735 & 0,00592 & 0,00670 & 0,00544 \\
A10 & 0,00446 & 0,00597 & 0,00540 & 0,00585 & 0,00699 \\
A11 & 0,00202 & 0,00371 & 0,00269 & 0,00358 & 0,00206 \\
A12 & 0,00456 & 0,00425 & 0,00471 & 0,00452 & 0,00375 \\
A13 & 0,00557 & 0,00311 & 0,00409 & 0,00340 & 0,00444 \\
A14 & 0,00239 & 0,00200 & 0,00243 & 0,00207 & 0,00127 \\
A15 & 0,00255 & 0,00104 & 0,00141 & 0,00100 & 0,00222 \\
A16 & 0,00086 & 0,00078 & 0,00104 & 0,00082 & 0,00162 \\
A17 & 0,00096 & 0,00031 & 0,00024 & 0,00029 & 0,00190 \\
\hline
\end{tabular}

Tablo 6: $d_{i j}$ Ağırlıklı Normalize Edilmiş Karar Matrisi

Eşitlik $\left(7_{a}\right)$ ve $\left(7_{b}\right)$ formülleri ile adım 3 'de bahsedilen faydalı ve faydasız ölçütler hesaplanmıștır ve Tablo 7.'de verilmiștir. Amaca ulaşmada yüksek değerlerin tercih edildiği katılımcı sayısı, katılımcı fon tutarı, devlet katkısı fon tutarı ve katkı payı tutarı faydalı ölçütlerin ( $\mathrm{Si}+$ ) hesaplanmasında kullanılırken, düşük değerlerin kullanıldığı faydasız ölçütlerin (Si-) hesaplanmasında emeklilik teknik gider kriteri kullanılmaktadır. 
Aynur Acer, Tolga Genç, Sait Erdal Dinçer, “Türkiye'de Faaliyet Gösteren Bireysel Emeklilik Şirketlerinin Performansının Entropi ve COPRAS Yöntemi ile Değerlendirilmesi”, İstanbul Gelişim Üniversitesi Sosyal Bilimler Dergisi, 7 (1), Nisan 2020, ss. 153-169.

\begin{tabular}{ccc}
\hline & Faydalı Ölçüt & Faydasız Ölçüt \\
Alternatifler & Si+ & Si- \\
\hline A1 & 0,14473 & 0,03649 \\
A2 & 0,14998 & 0,03401 \\
A3 & 0,12612 & 0,02218 \\
A4 & 0,09953 & 0,02366 \\
A5 & 0,06202 & 0,01356 \\
A6 & 0,04797 & 0,00730 \\
A7 & 0,04267 & 0,00781 \\
A8 & 0,02991 & 0,01057 \\
A9 & 0,02250 & 0,00544 \\
A10 & 0,02169 & 0,00699 \\
A11 & 0,01200 & 0,00206 \\
A12 & 0,01803 & 0,00375 \\
A13 & 0,01616 & 0,00444 \\
A14 & 0,00889 & 0,00127 \\
A15 & 0,00599 & 0,00222 \\
A16 & 0,00349 & 0,00162 \\
A17 & 0,00181 & 0,00190 \\
\hline T0PAM & 0,81350 & 0,18527 \\
\hline
\end{tabular}

Tablo 7: Faydalı ve Faydasız Ölçütler Tablosu

Adım 4'de yer alan Eşitlik 8'deki formül yardımıyla göreceli önem değerleri tablosu elde edilmiş ve Tablo 8.'de verilmiștir.

\begin{tabular}{llll}
\hline Alternatifler & Qi & Alternatifler & Qi \\
\hline A1 & 0,1459 & A10 & 0,0279 \\
A2 & 0,1513 & A11 & 0,0331 \\
A3 & 0,1281 & A12 & 0,0296 \\
A4 & 0,1014 & A13 & 0,0259 \\
A5 & 0,0652 & A14 & 0,0432 \\
A6 & 0,0539 & A15 & 0,0256 \\
A7 & 0,0482 & A16 & 0,0303 \\
A8 & 0,0340 & A17 & 0,0246 \\
A9 & 0,0305 & & \\
\hline
\end{tabular}

Tablo 8: Göreceli Önem Değerleri Tablosu

Adım 5 ve Eşitlik 9'da yer alan formül yardımıyla en yüksek göreceli önem değerine sahip alternatifin yer aldığı değer belirlenmektedir. Buna göre A2 alternatifinin yer aldığı Qmax değeri 0,1513 olarak elde edilmiştir. Son olarak Adım 6'daki Eşitlik 10 yardımı ile $P_{i}$ performans değer indeksi hesaplanmıștır ve bulgular aşağıda Tablo 9.'da verilmiștir. 


\begin{tabular}{lll}
\hline Alternatifler & Pi & Siralama \\
\hline A1 & 96,471 & 2 \\
A2 & 100,000 & 1 \\
A3 & 84,678 & 3 \\
A4 & 67,019 & 4 \\
A5 & 43,124 & 5 \\
A6 & 35,646 & 6 \\
A7 & 31,886 & 7 \\
A8 & 22,495 & 9 \\
A9 & 20,157 & 11 \\
A10 & 18,444 & 14 \\
A11 & 21,888 & 10 \\
A12 & 19,574 & 13 \\
A13 & 17,154 & 15 \\
A14 & 28,580 & 8 \\
A15 & 16,902 & 17 \\
A16 & 20,014 & 16 \\
A17 & 16,286 & 17 \\
\hline
\end{tabular}

Tablo 9: $P_{i}$ performans İndeksi Değerleri Tablosu

Yukarıda Tablo 9.'da verilen Pi performans İndeksi Değerleri incelendiğinde A2 şirketinin en yüksek performans değerine (100) sahip alternatif olduğu görülmektedir. Bu sıralamayı A1, A3, A4, A5, A6, A7, A14, A8, A11, A9, A16, A12, A10, A13, A15, A17 firmaları takip etmektedir.

\section{Sonuç ve Bulgular}

Dünya genelinde hem gelișmiş hem de gelişmekte olan ülkelerde uygulanan sosyal güvenlik sistemleri kriz, reform gibi bir takım nedenlerden dolayı birçok problemle karşı karşıya kalmış ve yeniden yapılanma ihtiyacını ortaya çıkarmıștır. Bu ihtiyacın bir sonucu olarak ortaya çlkan bireysel emeklilik sistemi ve bünyesinde oluşturulan özel fonlar sayesinde bireyler yatırım araçlarına yönlendirilmektedir. Makro düzeyde ekonomi ve uzun vadeli istikrarı olumlu yönde etkileyen, katılımcıları verimli yatırım araçlarına yönlendirerek emeklilikteki gelirlerini garanti altına alan ve kişilerin refah seviyelerini arttırmayı amaçlayan bir sistem olarak faaliyet göstermeyi amaçlayan bireysel emeklilik sistemi gönüllülük esasına dayalı bir sistemdir.

Bu çalışmada 2018 yılı verileri kullanılarak 17 BES șirketinin performansı COPRAS yöntemiyle sıralanmaya çalışılmıştır. Katılımcı sayısı, katılımcı fon tutarı, katkı payı tutarı, 
Aynur Acer, Tolga Genç, Sait Erdal Dinçer, “Türkiye'de Faaliyet Gösteren Bireysel Emeklilik Şirketlerinin Performansının Entropi ve COPRAS Yöntemi ile Değerlendirilmesi”, İstanbul Gelişim Üniversitesi Sosyal Bilimler Dergisi, 7 (1), Nisan 2020, ss. 153-169.

devlet katkısı fon tutarı ve emeklilik teknik gider kriterlerinin ağırlıklarının hesaplanmasında ise Entropi yöntemi kullanılmıştır. Entropi yöntemine göre önem derecesi en yüksek kriter katılımcı fon tutarı kriteridir. Kriterlerin agırlıklarına göre önem düzeyleri değerlendirildiğinde bu sıralamayı katkı payı tutarı, devlet katkısı fon tutarı, teknik gider ve son olarak katılımcı sayısı kriteri takip etmektedir. COPRAS yöntemine göre seçenekleri oluşturan BES şirketlerinin performansları sıralandığında A2, A1 ve A3 firması ilk üç firma arasında yer almaktadır. Bu sıralamayı sırasıyla A4, A5, A6, A7, A14, A8, A11, A9, A16, A12, A10, A13, A15, A17 şirketleri takip etmektedir. Çalışmanın çok kriterli karar verme yöntemlerinden biri olan COPRAS yönteminin sigortacllık ve BES şirketlerinin performans değerlendirilmesinde kullanılması nedeni ile literature katkı sağlayacağı düşünülmektedir.

\section{KAYNAKÇA}

ACER, A. \& DİNÇER E. S. (2018). Bireysel emeklilik şirketlerinin çok kriterli karar verme yöntemleriyle hibrit bir yaklaşimla değerlendirilmesi ve sıralanması. 19.

Uluslararasi EYI Sempozyumu Özet Bildiri Kitabi (17-20 Ekim). Antalya.

AKSOY, E., ÖMÜRBEK, N. \& KARAATLI, M. (2015). AHP temelli MULTIMOORA ve COPRAS yöntemi ile Türkiye Kömür İşletmeleri'nin performans değerlendirmesi. Hacettepe Üniversitesi İktisadi ve İdari Bilimler Fakültesi Dergisi. Cilt 33(4).

AKYÜZ, Y. \& KAYA, Z. (2013). Türkiye'de hayat dışı ve hayat/emeklilik sigorta sektörünün finansal performans analiz ve değerlendirilmesi. Selçuk Üniversitesi İktisadi ve İari Bilimler Fakültesi sosyal ve Ekonomik Araştırmalar Dergisi. Cilt 26. 355-371.

ALP, İ., ÖZTEL, A. \& KÖSE, M. S. (2015). Entropi tabanlı MAUT yöntemi ile kurumsal sürdürülebilirlik performansı ölçümü: bir vaka çalışması. Ekonomik ve Sosyal Araștırmalar Dergisi. Cilt 11(2). 65-81.

ANDRUŠKEVICIUS, A. (2005). Evaluation of contractors by using COPRAS - the multiple criteria method. Technological and Economic Development of Economy. 11(3). 158-169.

AYTEKIN, A. \& KARAMAŞA, Ç. (2017). Analyzing financial performance of insurance companies traded in BIST via fuzzy Shannon's entropy based fuzzy topsis methodology. Alphanumeric Journal. Cilt 5(1). 71-84. DOI:

10.17093/alphanumeric.323832.

BÜLBÜL, E. S. \& KÖSE, A. (2016). Türk sigorta sektörünün PROMETHEE yöntemi ile finansal performans analizi. Marmara Üniversitesi İktisadi ve İdari Bilimler Dergisi. Cilt 38(1). 187-210.

CHATTERJEE, P. \& CHAKRABORTY, S. (2012). Material selection using preferential ranking methods. Materials and Design. 35. 384-393.

CUMMINS, J. D., SHARON, T. \& MARY, A. W. (1998). Consolidation and efficiency in the U.S life insurance industry. Center of Financial Instutions Working Paper. 98-08. Wharton School Center for Financial Institutions. University of Pennsylvania.

ÇAKIR, S. (2016). Türk sigortacılık sektöründe çok kriterli karar verme teknikleri (ÇKKV) ile performans ölçümü: BIST uygulaması. Çukurova Üniversitesi İktisadi ve İdari Bilimler Fakültesi Dergisi. Cilt 20(1). 127-147.

ÇAKIR, S. \& PERÇIN, S. (2013). AB ülkelerinde bütünleşik entropi ağırlık-TOPSIS yöntemleriyle arge performanslarının ölçülmesi, Uludağ Üniversitesi. Íktisadi ve İdari Bilimler Fakültesi Dergisi. XXXII (1). 77-95 
Aynur Acer, Tolga Genç, Sait Erdal Dinçer, “Türkiye'de Faaliyet Gösteren Bireysel Emeklilik Şirketlerinin Performansının Entropi ve COPRAS Yöntemi ile Değerlendirilmesi”, İstanbul Gelişim Üniversitesi Sosyal Bilimler Dergisi, 7 (1), Nisan 2020, ss. 153-169.

ÇINAR, Y. (2004). Çok nitelikli karar verme ve bankaların mali performanslarının değerlendirilmesi örneği. Ankara Üniversitesi Sosyal Bilimler Enstitüsü İşletme Anabilim Dal. Yüksek Lisans Tezi, Ankara.

ÇIFTÇI, H. (2004). Türk sigorta sektörünün sorunları: DEA analizi ile Türk sigorta şirketlerinin etkinlik düzeylerinin belirlenmesi. Çukurova Üniversitesi Sosyal Bilimler Enstitüsü Dergisi. 13-1.121-143.

DAĞDEVIREN M. \& EREN, T. (2001). Tedarikçi firma seçiminde analitik hiyerarşi prosesi ve 0-1 hedef programlama yöntemlerinin kullanılması. Gazi Üni., Müh. Mim. Fak. Der., cilt 16/2. 41-52.

DALĞAR, H. (2007). Kurumsal yatırımcılar olarak emeklilik yatırım fonları ve performanslarının değerlendirilmesi. Türkiye Bankalar Birliği. Yayın No: 249.

DALKILIÇ, N. (2012). Türkiye'de hayat dışı sigortacıllk sektöründe etkinlik analizi. Muhasebe ve Finansman Dergisi. Cilt (55). 71-90.

EGE, İ., TOPALOĞLU, E. E. \& COŞKUN, D. (2011). Türkiye'deki emeklilik yatırım fonlarının yatırım performanslarının analizi, Ekonomi Bilimleri Dergisi, 3(1). 79-89.

Emeklilik Gözetim Merkezi (2017). Bireysel Emeklilik Sistemi Gelişim Raporu. Erișim Tarihi: 10.02.2019, https://www.egm.org.tr/bilgi-merkezi/yillik-gelisimraporlari/

Emeklilik Gözetim Merkezi (EGM). Erişim Tarihi: 10.02.2019, http://www.egm.org.tr

FAN, C. K. \& CHENG, S.W. (2009). Using analytic hierarchy process method and technique for order preference by similarity to ideal solution to evaluate curriculum in department of risk management and insurance. Journal of Science in Society, Vol.19-1.1-8.

GAZETE, Resmi (2001). Bireysel Emeklilik Tasarruf ve Yatırım Sistemi Kanunu. Erişim Tarihi: 07.03.2019, 07.04 2001 tarihli ve 24366 sayılı Resmi Gazete. https://www.resmigazete.gov.tr/eskiler/2016/08/20160825-4.htm

GAZETE, Resmi (2017). Çalıssanların İşverenleri Aracılığıyla Otomatik Olarak Emeklilik Planına Dâhil Edilmesine İliş̧in Usul ve Esaslar Hakkında Yönetmelik. Erişim Tarihi: 08.04.2019, Hazine Müsteșarlığı. www.tsb.org.tr

GENÇ, T. (2013). PROMETHEE yöntemi ve GAIA düzlem. Afyon Kocatepe Üniversitesi İIBF Dergisi, 15(1). 121-142.

GENÇ, T., KABAK, M., KÖSE, E., \& YILMAZ, Z. (2015). Bireysel emeklilik sistemi seçimi problemine ilişkin Macbeth yaklașımı. İstanbul Üniversitesi Íktisat Fakültesi Ekonometri ve Istatistik Dergisi. (22). 47-65.

GÖKTOLGA, Z. G., \& KARAKIŞ, E. (2018). Bireysel emeklilik şirketlerinin finansal performanslarının bulanık AHP ve VIKOR yöntemi ile analizi. Cumhuriyet Üniversitesi Íktisadi ve İdari Bilimler Dergisi. 18(1). 92-108

HAO, J. CJ. \& LIN-YHI C. (2005), The estimation of efficiency for life insurance industry: the case in Taiwan, Journal of Asian Economics. Vol.16. 847-860.

KAKLAUSKAS, A., ZAVADSKAS, E.K., BANAITIS, A. \& SATKAUSKAS, G. (2007). Defining the utility and market value of a real estate: a multiple criteria approach. International Journal of Strategic Property Management. 11(2). 107-20.

KÖSE, A. (2010). Türk sigorta sektörü hayat ve emeklilik şirketleri etkinlik analizi. Akademik Araştırmalar Dergisi. 44. 85-100.

KSENIJA, M., BORIS, D., SNEŽANA, K., \& SLADJANA, B. (2017). Analysis of the efficiency of insurance companies in Serbia using the fuzzy AHP and TOPSIS methods. Economic research-Ekonomska istraživanja. 30(1), 550-565.

KULA, V., KANDEMIR, T., \& BAYKUT, E. (2016). Borsa istanbul'da işlem gören sigorta ve BES şirketlerinin finansal performansının gri ilişkisel analiz yöntemi ile incelenmesi. AKÜ İIBF Dergisi, 18(1), 37-53. 
Aynur Acer, Tolga Genç, Sait Erdal Dinçer, “Türkiye'de Faaliyet Gösteren Bireysel Emeklilik Şirketlerinin Performansının Entropi ve COPRAS Yöntemi ile Değerlendirilmesi”, İstanbul Gelişim Üniversitesi Sosyal Bilimler Dergisi, 7 (1), Nisan 2020, ss. 153-169.

ÖZCAN, N. \& ÖMÜRBEK, A. (2016). BIST'de işlem gören sigorta şirketlerinin multımoora yöntemiyle performans ölçümü. International Journal of Business Economics and Management Perspectives. 1(2), 65-75.

ÖZDAĞOĞLU, A. (2014). İmalat işletmeleri için eksantrik pres alternatiflerinin copras yöntemi ile karșllaştırılması. Gümüşhane Üniversitesi Sosyal Bilimler Enstitüsü Elektronik Dergisi. 4(8). 1-12.

ÖZER, A. C., \& GÜREL, H. (2014). Türkiye'de bireysel emeklilik sistemi bilgi düzeyi ve Bes' e katılımda devlet katkısının etkisi üzerine bir araştırma. Mustafa Kemal Üniversitesi Sosyal Bilimler Enstitüsü Dergisi. 11(27).

PEKER, I., \& BIRDOĞAN, B. (2011). Gri ilișkisel analiz yöntemiyle türk sigortacılık sektöründe performans ölçümü. Uluslararası İktisadi ve İdari İncelemeler Dergisi, (7).

PERÇIN, S. \& SÖNMEZ, Ö. (2018). Bütünleşik entropi ağırlık ve TOPSIS yöntemleri kullanılarak türk sigorta șirketlerinin performansının ölçülmesi. Uluslararası İktisadi ve İdari Incelemeler Dergisi, 18, 565-582.

PODVEZKO, V. (2011), The comparative analysis of mcda methods saw and copras. Inzinerine Ekonomika-Engineering Economics. 22(2), 134-146.

SHANNON, C. E. (1948). A mathematical theory of communication. Bell System Technical Journal, 27(3), 379-423.

ŞEN, M. \& Memiş, T. (2000). Özel emeklilik ve Türkiye için sistem önerisi. TUGİAD Ekonomi Ödülleri Kitabı.

ŞENER, O. \& AKIN, F. (2010). Özel emeklilik fonları ve türkiye'de bireylerin bireysel emeklilik sistemine giriş kararlarını etkileyen faktörlerin belirlenmesi üzerine bir araștırma. Marmara Üniversitesi İktisadi ve Ídari Bilimler Dergisi. 29(2), 291-321.

TUNCA, M. Z., ÖMÜRBEK, N., CÖMERT, H. G., \& AKSOY, E. (2016). OPEC

ülkelerinin performanslarının çok kriterli karar verme yöntemlerinden entropi ve MAUT ile değerlendrilmesi. Vizyoner Dergisi, 7(14), 1-12.

Türkiye Sigorta Reasürans ve Emeklilik Şirketleri Birliği, (TSB),

https://www.tsb.org.tr/ (Erișim Tarihi: 10.02.2019)

ZAGORSKAS J., BURINSKIENE, M., ZAVADSKAS, E.K. \& TURSKIS, Z. (2007).

Urbanistic assessment of city compactness on the basis of GIS applying the copras method. Ekologija, 53. 55-63.

ZAVADSKAS, E. K. \& KAKLAUSKAS, A. (1996). Systemotechnical evaluation of buildings (pastatų sistemotechninis įvertinimas). Vilnius: Technika, 280 p. (in Lithuanian).

ZAVADSKAS, E. K., KAKLAUSKAS, A., BANAITIS, A. \& KVEDERYTĖ, N. (2004). Housing credit access model: the case for Lithuania. European Journal of Operational Research, 155(2). 335-352.

ZAVADSKAS, E. K., KAKLAUSKAS, A., TURSKIS, Z., \& TAMOŠAITIENĖ, J. (2008). Contractor selection multi-attribute model applying copras method with grey interval numbers. 20th EURO Mini Conference Continuous Optimization and Knowledge-Based Technologies (EurOPT-2008), May 20-23, 2008, Lithuania.

ZAVADSKAS, E.K., KAKLAUSKAS, A., PELDSCHUS, F. \& TURSKIS, Z. (2007). Multiattribute assessment of road design solution by using the copras method. The Baltic Journal of Road and Bridge Engineering, 2(4). 195-203.

\section{Summary}

The social security system, which varies from country to country all around the world, supports the capital market. However, social security faces the deep crises and 
requires reforms. By employing insurance firm's private superannuation plans and reconstruct their own systems, social security systems try to reduce risks. Financially developed countries employ complementary private superannuation for a long time. On the other hand, Turkey started to complementary private super annuation in 27th October 2003. Private superannuation funds have a massive share in insurance industry. Insurance industry diverts those funds to long term investments, not only to guarantee the participants pensions and provide them an extra income in their retirement, but also to ease the existing social security system's burdens. Joining the private superannuation based on volunteering principle. Furthermore, this system mainly aims to effect economical macro terms and longterm stability in positive ways, least but not last, this system aims to increase, not only, employees, but also, pensions welfare. That's why private superannuation companies's performance and effectiveness measurement become more and more important both companies and individuals.

In this study, the performance of the BES Company operates in Turkey ordered by Entropy and COPRAS. Literature review and expert opinions were included in the determination of the criteria included in the evaluation and as a result, five criteria were determined: the number of participants, participant fund amount, contribution amaunt, the state contribution amaunt and retirement technical expence. Entropy method was primarily used in the calculation of criterion weights. According to the method, the criterion with the highest weight is determined as the amount of participant funds and this criterion was followed by the contribution amount, the state contribution fund amount, the retirement technical expense and finally the number of participants. Among the 17 private pension companies evaluated using the COPRAS method steps, $A 2, A 1$ and $A 3$ are the best performing BES companies. these companies are followed by $A 4, A 5, A 6, A 7, A 14, A 8, A 11, A 9, A 16, A 12$, A10, A13, A15 and A17 respectively. In this study, the COPRAS method was used for the first time in evaluating the performance of private pension companies in the insurance sector. In future researches, it can be evaluated whether there is a difference between the results by using other multi-criteria decision making methods. 